\title{
Development of Wall Construction Material Stabilized with Enset Vegetable Fibers for Rural Housing Units
}

\author{
Eshetu Esayas $^{1, *}$, Elmer C Agon², Sintayehu Assefa ${ }^{3}$ \\ ${ }^{1}$ Jimma University, Jimma Institute of Technology Department of Architecture and Urban Planning, Jimma Ethiopia \\ ${ }^{2}$ Jimma University, Jimma Institute of Technology, Chair of structural engineering, Jimma Ethiopia \\ ${ }^{3}$ Jimma University, Jimma Institute of Technology, Construction Engineering and Management Chair, Jimma Ethiopia \\ *Corresponding author: eshe511@gmail.com
}

\begin{abstract}
The need to develop affordable and durable housing is necessary for both urban and rural dwellers. This study was an attempt to alleviate the building material problem faced in rural dwelling units of these countries by developing nonstructural earthen wall construction material stabilized with enset vegetable fibers. Enset fiber is traditionally harvested from leaves of enset plant as end or byproduct of 'kocho'. To bring this material in to construction industry the researcher studied its properties and strength as reinforcing material. The dry density of FREB decreased for increased fiber content from $0 \%-5 \%$ and minimum dry density of block at fiber $1.5 \%$ of the block. For increased fiber content in FREB, water absorption test failed $0 \%-1 \%$ of fiber content and for $1.5 \%-5 \%$ of fiber content, water absorption is high and the standard specification of water absorption found at $1.5 \%$ of fiber content block. Compressive strength of FREB in accordance with ASTM C116-90 is difficult and durability of FREB is done using water absorption and other tests; whereas the flexural strength of FREB is increased with increasing amount of fiber in block. That the researcher highly recommend, earthen block reinforced with enset fiber is low cost, simplest, easily shaped during casting, available where enset growing regions, low energy input, durable when casted properly and plastered well and environmental friendly.
\end{abstract}

Keywords: enset vegetable fiber, compressive strength, reinforce

Cite This Article: Eshetu Esayas, Elmer C Agon, and Sintayehu Assefa, "Development of Wall Construction Material Stabilized with Enset Vegetable Fibers for Rural Housing Units.” American Journal of Civil Engineering and Architecture, vol. 6, no. 2 (2018): 54-62. doi: 10.12691/ajcea-6-2-2.

\section{Introduction}

Ethiopia has more than 86 million population and among them 11 million is living in urban area and the left 75 million is rural dwellers CSA 2007 E.C.

These all rural dwellers are using different construction materials and methods based on the availability of materials, their cultures and climatic conditions of the area [1]. Among the materials they used, wood, thatch and mud are the most common. However, the method and techniques they used are traditional way [1]. Historically, earth has been the most widely known and used as building material in construction and probably has been the most important of all building materials [2].

Ethiopia has its traditional technology for the construction of dwellings. Houses built with this technology may adopt both circular and rectangular shape.

According to [3] in the world currently, around $30 \%$ of populations live in earth-made constructed home. Nowadays $50 \%$ of the population in developing countries, including the majority of the rural population and at least $20 \%$ of the urban and suburban population, live in earthen houses.

Unfortunately, the traditional building techniques adopted for mud walls from study area have serious defects. The mud walls suffer from extended shrinkage cracks, which weaken the walls [4]. Mud walls can easily be eroded by rain. Sometimes, the mud walls have been covered with protective coating consisting of animal dung. The protective surface needed continued maintenance and sometimes renewal almost every year [5]. These entire drawbacks lead most of the people to the misconception that buildings with soil are of inferior quality and should be avoided. Since the awareness of the people in low degree, majority of the dwellers constructing their house with wood as wall and thatch as covering material. According to [6], people built their house with wood and thatch. Houses constructed with wood and thatch were easily affected by termite, less durable and poor indoor climate.

The past researchers investigated mud construction, on the durability of mud block stabilized with cement and lime or waterproofing agents like bitumen do significantly improve the strength of compressed earth blocks. These additives are, however, accompanied by increase in costs of material; this is not sustainable especially for the poor rural communities of the developing nations. It is the aim of the present investigation to show that these traditional binders can be replaced by environmentally friendly, locally available and sustainable alternatives i.e. enset fibers. 


\section{Materials and Methods}

\subsection{Materials}

The basic materials used in this research were clay soil, enset vegetable fiber or Enset ventricosum fiber from Dawro zone and clean water.

\subsection{Clay Soil}

The field investigation or soil exploration is taken from Dawro zone near to Tarch town particularly called Sore neighborhood. By excavating a test pit is from observational based as they are using soil for home clay products. It is taken from $50 \mathrm{~cm}$ depth in order to prevent organic matter from top soil.

Soil exploration is necessary to investigate the behavior and nature of the soil mass under different conditions. The exploration can be performed by field and laboratory tests. All the tests are performed based on ASTM standard and AASHTO for soil testing. The tests included in this report are specific gravity, Atterberg's limit, and grain size analysis

\subsection{Enset Fiber}

The fiber, with a hair like structure, locally called "kacha" is collected after scarping of the leaf sheath and leaf bases around the pseudo stem. The inner part of the pseudo stem is simply discarded as waste. These residues are abundant natural resources and can be potential source of cellulosic fiber. The extraction process is manually production for the purpose of to get food 'kocho' and this material is also collected from the study area from markets and logged in to Jimma University Jimma institute of technology laboratory and JUCAVM. See Figure 1.

\subsection{Water}

Tap water was used for all aspects of block production and experimental analysis of soil testing.

\subsection{Study Design}

The study design of this research was experimental in nature, collecting research materials from the study area and making laboratory tests for its properties. It was taking soil from $50 \mathrm{~cm}$ depth by removing top soil and conducting the relevant study on it, then drying the soil, crashing, sieving and mixing with stabilizer to make FREB.

Enset fiber was collected from local market of study area and tested in the laboratory, then chopped in to $1-1.5 \mathrm{~cm}$ and mixed with soil and water. Chopping of fiber in to this unite is based on past investigators recommendation in order to have uniform dry mix of soil and fiber. Wooden mold prepared according to Golden ratio theory and Fibonaci series numbers. The mold size is $9 \mathrm{~cm}$ height, $15 \mathrm{~cm}$ width and $24 \mathrm{~cm}$ length. After mold casted curing, measuring, crashing and discussing the result is the basic concept of the researcher.

\subsection{Experimental Work Procedures of Materials}

\section{Properties and strength of Enset vegetable fiber Enset fiber}

The required enset vegetable fiber collected from local market from study area and dried under room temperature at the same time with clay soil. It is minimum $1 \mathrm{~m}$ and maximum of $1.5 \mathrm{~m}$ long as shown in Figure 2. In order to mix it with clay, the fiber was chopped in $1-1.5 \mathrm{~cm}$ long. The chopped fiber weighted according to mass ratio of the soil and ranges from $0.5-5 \%$.

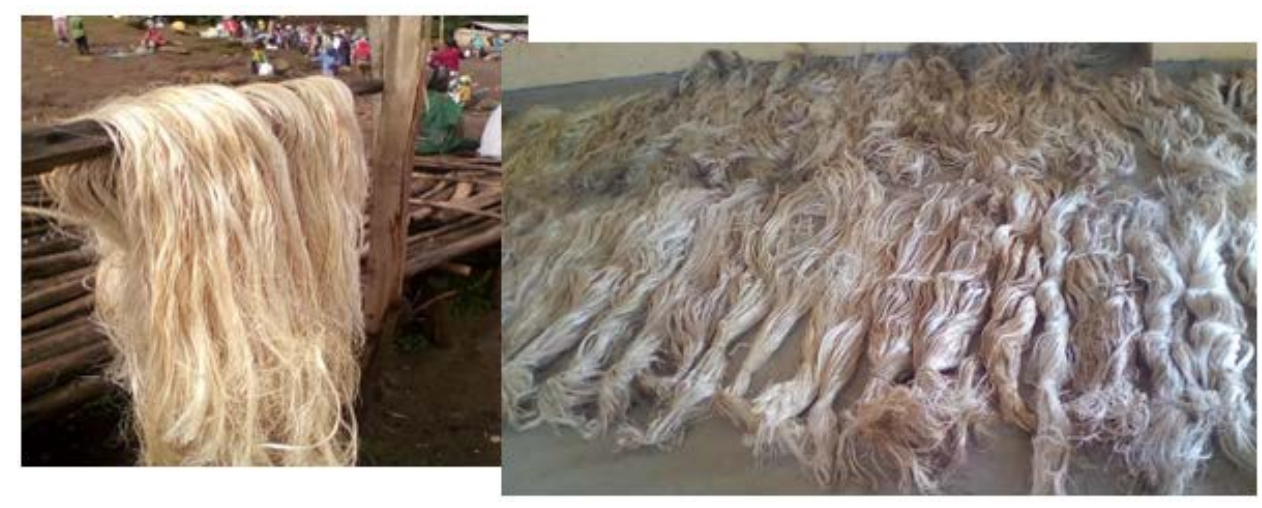

Figure 1. Enset fiber from market and drying in room temperature in laboratory

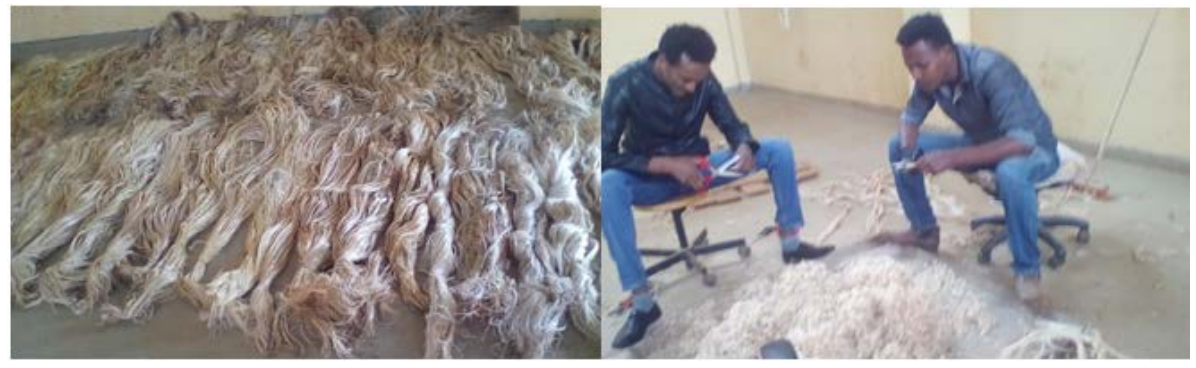

Figure 2. Fiber for mix preparation 


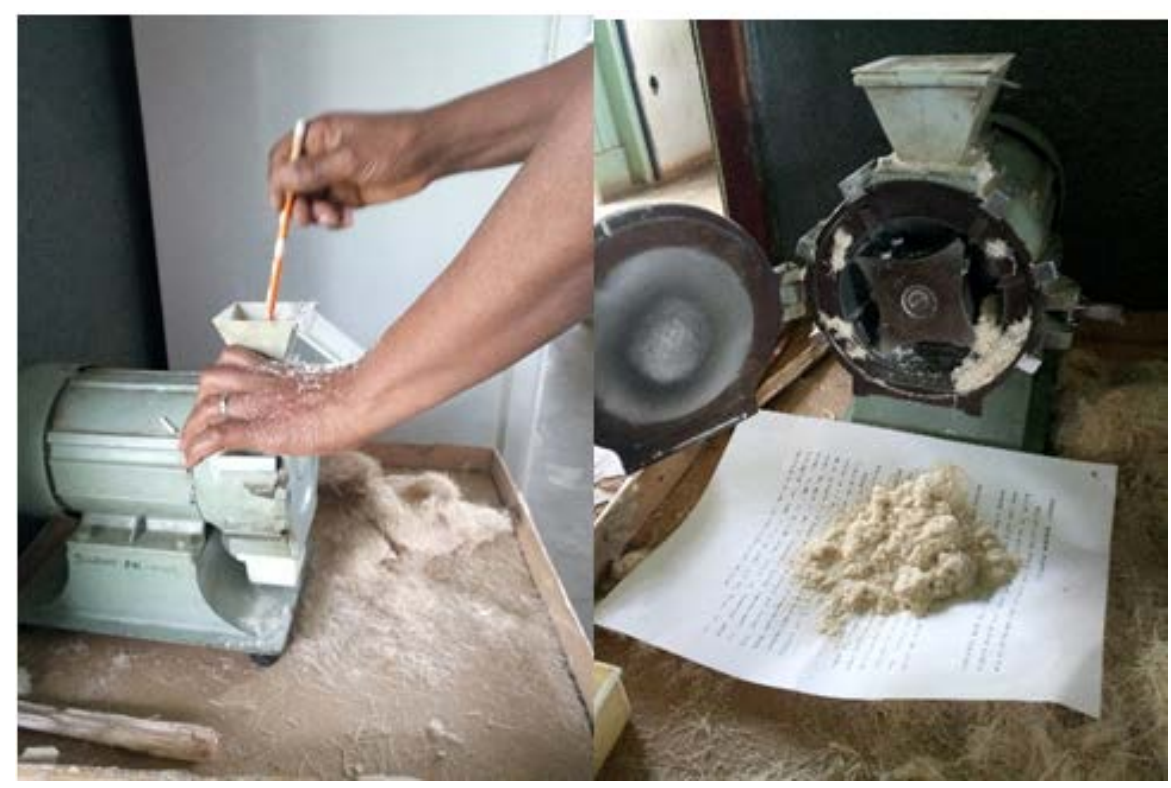

Figure 3. Enset fiber grinding for organic content test

\section{Organic content enset fiber}

For this test first $1-1.5 \mathrm{~mm}$ chopped fiber weight $50 \mathrm{gm}$ dried in oven for $105-110^{\circ} \mathrm{C}$ for 24 hours and then then grinded in in machine named FZ 102 MCRO plant grinding machine as shown in Figure 3. The machine works manually adding fiber on the top cylindrical shaped body and inside it is rotating and grinding then passed to the bottom with $2 \mathrm{~mm}$ sieve size.

\section{Moisture content of the fiber}

Moisture content of enset fiber is tested accordance with the moisture content of clay soil stated and calculated as Equation 1.

$$
w=\frac{M_{w}}{M_{s}} \times 100
$$

Where, $\mathrm{w}=$ moisture content of soil, in $\%$ and $\mathrm{M}_{\mathrm{w}}=$ mass of water in soil sample.

\section{Density of enset fiber}

Due to the irregularities observed in the cross section areas of a bundle of enset fibers, the Archimedes principle was used to determine the apparent density of the enset vegetable fibers. The procedure was to immerse in benzene a known weight of enset fibers and finally using Equation 2, the apparent density value of the enset fibers was obtained. Benzene was chosen because of its low density value $\left(690 \mathrm{~kg} / \mathrm{m}^{3}\right)$ [7].

$$
\rho b=\rho s \frac{M a}{M a-M_{s}} \times 100
$$

Where, $\rho_{\mathrm{b}}=$ Density of henequen/fiber, $\rho_{\mathrm{s}}=$ Density of solvent, $\mathrm{Ma}=$ Mass of henequen fiber in air, Ms = Mass of henequen fiber in solvent

\section{Tensile strength of single fiber/pull}

The tensile strengths and stiffness of the fiber bundles were measured using an Instron 1122 equipment [8]. Due to the lack of equipment the researcher used to test single fiber strength combining the Gonzalez (2012) and Ermiyas (2011) pull-out test. Measuring the diameter of fiber dimension using digital caliper and calculated as Equation 3. Then the single fiber srength is calculated as using Equation 3.

$$
\sigma=\frac{F}{\left(\frac{m}{\rho l}\right)}
$$

Where, $\mathrm{F}=$ force applied at failure $(\mathrm{N}), \sigma=$ tensile stress, $\mathrm{m}=$ mass of the fiber $(\mathrm{kg}), \mathrm{l}=$ length of the fiber $(\mathrm{m}), \rho=$ density of the fiber $\left(\mathrm{kg} / \mathrm{m}^{3}\right)$

\section{Strength property of fiber reinforced earthen block}

\section{Fiber reinforced earthen block production}

It is both manual or mechanical, mathematical and other effort to achieve the respective block based on the literature suggestion, standard reference and laboratory test technique and discussed as follows.

\section{Earth preparation and characterization}

Full blocks were fabricated using soil collected from Tarcha Town Sore neighbor. In order to obtain initial uniform moisture content, the soil was stored in the open at a room temperature of $22{ }^{0} \mathrm{C}$ at a relative humidity of 65 - $70 \%$ for one months before being broken down and passed through a $2 \mathrm{~mm}$ sieve. The soil has been, through crushing and sieving, prepared with particular care, in order to ensure that the enset fiber or reinforcing agent could be uniformly distributed throughout the material.

The overall soil preparation is illustrated as blow diagram Figure 4.

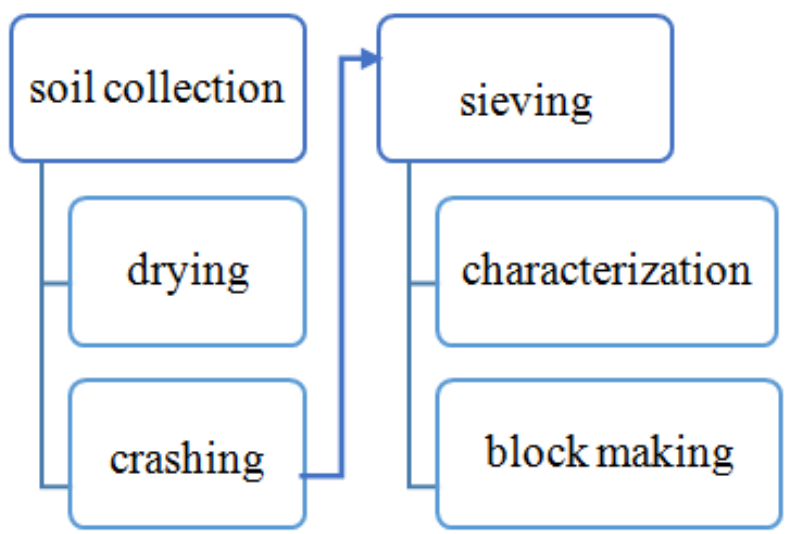

Figure 4. Soil preparation process 


\section{Mold size determination}

Mold size determined according with architectural theory of proportion by Golden ratio using Fibonacci series numbers. They are in whole number series $1,2,3,5$, $8,13,21,34,55,89 \ldots$ infinite [9]. Each term is again is the sum of the two preceding ones and the ratio between two consecutive terms tends to approximate the Golden Section as the series progress to infinity. The ratio of this two number is for example $3 / 2,5 / 3,8 / 5,13 / 8 \ldots$ approximately 1.6. In this number series my block size are between 8 and 40. For example if I start from number 5 as height of my block the next numbers of this series are 8 and 13 which are width and length for my block but this cannot fulfill any of wall size. So in this study I started number 8 which is from the series and the next two numbers are 13 and 21 . In this case the block has 8,13 and $21 \mathrm{~cm}$ of height, width and length respectively. But the block width must confirm the wall thickness so doing another modification to these numbers which cannot distort golden ratio 1.6 so $1: 2: 3$ are added orderly to this numbers and it becomes 9,15 and 24 . Now the width of the block is $15 \mathrm{~cm}$ and it can fulfill $15 \mathrm{~cm}$ thick wall and still these numbers (width to height, length to width, 15/9, $24 / 15$ is 1.6) Golden ratio.

\section{Fiber content determination}

The amount of fiber added in each mold is taking the sample weight of the dry mass of the soil in single mold and calculated as the percent amount of each mold. The mass of dry soil added in manually prepared box from Golden ratio $9 * 15 * 24$ is $3.875 \mathrm{Kg}$. Then fibers added in each block are starting from $0.5-5 \%$ in 0.5 interval. The amount of fiber added and number of blocks produced are shown in Table 1.

Table 1. Fiber content used in kilogram

\begin{tabular}{cccccc}
\hline No & $\begin{array}{c}\text { Mass of } \\
\text { soil mold } \\
\mathbf{( K g )}\end{array}$ & $\begin{array}{c}\text { Fiber } \\
\mathbf{( \% )}\end{array}$ & $\begin{array}{c}\text { No of } \\
\text { blocks }\end{array}$ & $\begin{array}{c}\text { Mass of } \\
\text { fiber per } \\
\text { mold (Kg) }\end{array}$ & $\begin{array}{c}\text { Total mass } \\
\text { of fiber } \\
\text { used (Kg) }\end{array}$ \\
\hline $\mathbf{1}$ & 3.875 & 0 & 4 & 0 & 0 \\
$\mathbf{2}$ & 3.875 & 0.5 & 4 & 0.019375 & 0.0775 \\
$\mathbf{3}$ & 3.875 & 1 & 4 & 0.03875 & 0.155 \\
$\mathbf{4}$ & 3.875 & 1.5 & 4 & 0.058125 & 0.2325 \\
$\mathbf{5}$ & 3.875 & 2 & 4 & 0.0775 & 0.31 \\
$\mathbf{6}$ & 3.875 & 2.5 & 4 & 0.096875 & 0.3875 \\
$\mathbf{7}$ & 3.875 & 3 & 4 & 0.11625 & 0.465 \\
$\mathbf{8}$ & 3.875 & 3.5 & 4 & 0.135625 & 0.5425 \\
$\mathbf{9}$ & 3.875 & 4 & 4 & 0.155 & 0.62 \\
$\mathbf{1 0}$ & 3.875 & 4.5 & 4 & 0.174375 & 0.6975 \\
$\mathbf{1 1}$ & 3.875 & 5 & 4 & 0.19375 & 0.775 \\
Total & & & 44 & 1.065625 & 4.2625 \\
\hline
\end{tabular}

\section{Block production}

For the comparison purpose of compressive strength of earthen block sieved and passed under $2 \mathrm{~mm}$ sieve and clay soil mixed with clean water until it become wet and blended with hands and legs smoothly. In the next step as its percent unit mass enset fiber added in to the soil passed in $2 \mathrm{~mm}$ sieve in dry condition and mixed uniformly in dry condition. Water is added until the material wet or workable for the production and blended with legs, hands and shovel together repeatedly. To get required compaction in the block the prepared past dropped from the height of $1 \mathrm{~m}$ to the mold box and the extra paste is trimmed from the box. To remove safely the fresh mold from the box, the mold box lubricated with ash/cinder and easily removed and put in curing place.

\section{Curing method of earthen block}

More attention is given for fresh earthen block in order to avoid breakage; particularly to the block ages. In this case all the blocks are air dried in the laboratory under room temperature and to easily evaporate the moisture from the block wooden plank is used. The room temperature of the laboratory is between $20-23^{\circ} \mathrm{C}$ and based on literatures it takes 45 days blocks to dry before test in compressive machine.

\section{Compressive strength test}

For compressive strength testing 30 piece enset fiber reinforced block casted based on fiber percent mass, for each trial of fiber 3 blocks are produced, whereas, for comparison case 3 blocks which are no fiber reinforced are casted and tested. The left 11 blocks are used for different tests like water observation and proofing. The test method is done as Equation 4.

$$
W C S=\frac{M_{L}}{A_{S}}
$$

Where: WCS = wet compressive strength $(\mathrm{MPa}), \mathrm{M}_{\mathrm{L}}=$ maximum load $(\mathrm{KN}), \mathrm{A}_{\mathrm{S}}=$ cross section area $\left(\mathrm{mm}^{2}\right)$.

\section{Flexural strength test}

For this test two type of fiber length used namely; fiber chopped into $1-1.5 \mathrm{~cm}$ with the same process of blocks made for compressive strength. In this method using dry mass of soil for one block percent two molds are produced for comparison with non-cut length of fiber. The other method is cutting fiber equal with block length $(50 \mathrm{~cm})$ and laying the fiber inside the mud to the longest direction. In this method fiber added to the block $1 \%, 2 \%$ and $3 \%$, however for the first method the fiber amount is only $2.5 \%$.

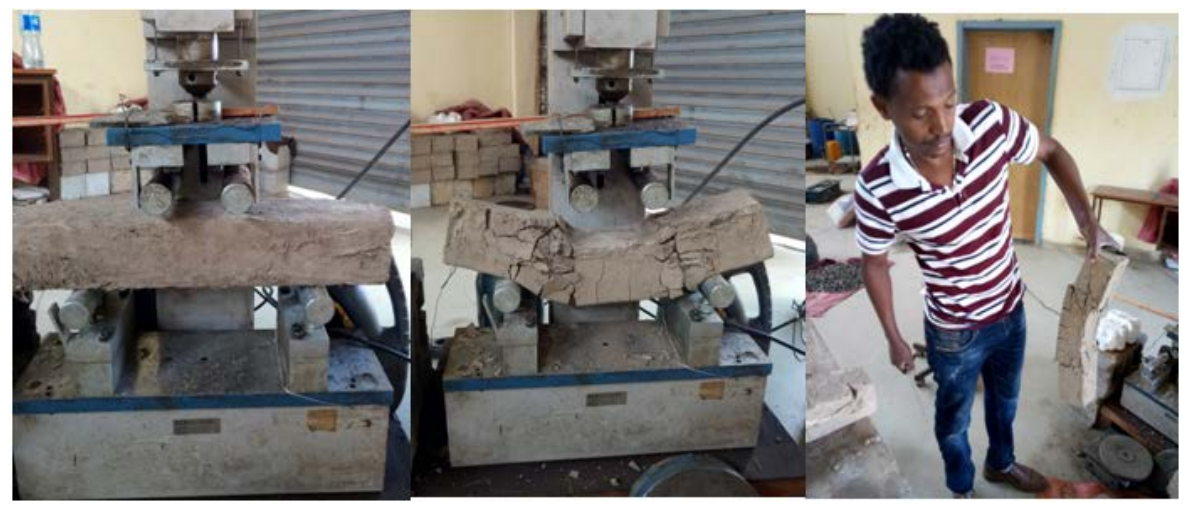

Figure 5. Flexural test of the sample block 
The mold dimension is $50 \mathrm{~cm} * 10 \mathrm{~cm} * 10 \mathrm{~cm}$ and volume of $0.005 \mathrm{~m}^{3}$, whereas the dry mass of the mold box can hold is approximately 6kg. Two molds are casted for each fiber content for accuracy and test sample is shown in Figure 5.

\section{Water absorption}

Water absorption test is a test conducted over 24 hours to determine the quantity of water absorbed by a block. At first, cured specimens are air dried for a day and then it is immersed in water for 24 hours [10]. It is weighed again the following day and the quantity of water absorbed by the block is ascertained as a percentage of its initial mass calculated as Equation 5.

$$
W w=\frac{M 2-M 1}{M 1} * 100
$$

Where, $\mathrm{Ww}_{\mathrm{w}}=$ weight of water in percent, M1= mass of block before immersed to water (Kg), M2 = mass of block after water $(\mathrm{Kg})$.

\section{Result and Discussion}

\subsection{Properties and Strength of Enset Vegetable Fiber and Discussion}

\section{a. Organic content of sample fiber}

Test result indicates that enset fiber contains 62\% cellulose, hemicellulose $19 \%$ and lignin 5\%. Several literatures suggest that enset fibers have industrial application, pharmaceutical and other. According to De Assis as cited in [11] enset fibers have many advantages for industerial application like water proof and UV protection. According to Cambrage and English dectionary cellulose is a complex carbohydrate that forms the main constituent of the cell wall in most plants and is important in the manufacture of numerous products, such as paper, textiles, pharmacceuticals and explosives.

\section{b. Single fiber strength test of sample}

The test result using Equation 2 and 3 the average stress is $0.2316 \mathrm{~N} / \mathrm{mm}^{2}$. The fiber diameter measured in digital caliper and force applied to break or snap the fiber are in Table 2. From this table we can observe that for increased fiber diameter the force applied is also increased and the average force for 10 sample is $15.44 \mathrm{~N}$.

Table 2. Fiber strength measurement

\begin{tabular}{cccc}
\hline $\begin{array}{c}\text { Fiber Diameter } \\
(\mathbf{m m})\end{array}$ & $\begin{array}{c}\text { Mass of } \\
\text { water (Kg) }\end{array}$ & Force (N) & $\begin{array}{c}\text { Stress (a) } \\
\mathbf{N} / \mathbf{m m}^{2}\end{array}$ \\
\hline $\mathbf{0 . 0 7}$ & 1.07 & 10.4967 & 0.157451 \\
$\mathbf{0 . 0 7}$ & 1.06 & 10.3986 & 0.155979 \\
$\mathbf{0 . 1 4}$ & 1.21 & 11.8701 & 0.178052 \\
$\mathbf{0 . 1 4}$ & 1.54 & 15.1074 & 0.226611 \\
$\mathbf{0 . 1 8}$ & 1.64 & 16.0884 & 0.241326 \\
$\mathbf{0 . 1 8}$ & 1.6 & 15.696 & 0.23544 \\
$\mathbf{0 . 2 1}$ & 1.67 & 16.3827 & 0.245741 \\
$\mathbf{0 . 2 1}$ & 2 & 19.62 & 0.2943 \\
$\mathbf{0 . 2 1}$ & 1.91 & 18.7371 & 0.281057 \\
$\mathbf{0 . 2 1}$ & 2.04 & 20.0124 & 0.300186 \\
Average & & 15.44094 & 0.231614 \\
\hline
\end{tabular}

From Table 2 minimum diameter of Enset vegetable fiber sample is $0.07 \mathrm{~mm}$ and the maximum is $0.21 \mathrm{~mm}$ where the researcher used sample. The strength of fiber is directly proportion with fiber diameter seen on Table 2 at the end column.

\section{c. Moisture content test of the specimen}

Moisture content of the enset vegetable fiber is tested in accordance with ASTM D 2216 stated and the test result is illustrated in Table 3.

Table 3. Moisture content of enset vegetable fiber

\begin{tabular}{lccc}
\hline Determination No & $\mathbf{1}$ & $\mathbf{2}$ & $\mathbf{3}$ \\
\hline Container name & ATR & T1 LB & NC 63 \\
W $_{0}$ = weight of container & 23.468 & 23.967 & 22.912 \\
$\mathrm{~W}_{1}$ = weight of container + wet fiber & 28.103 & 27.888 & 26.807 \\
$\mathrm{~W}_{2}$ = weight of container + oven dry fiber & 27.439 & 27.352 & 26.333 \\
$\mathrm{~W}_{1}-\mathrm{W}_{2}=$ weight water & 0.666 & 0.536 & 0.474 \\
$\mathrm{~W}_{2}-\mathrm{W}_{0}=$ weight of dry fiber & 3.971 & 3.385 & 3.421 \\
Moisture content & 16.721 & 15.835 & 13.856 \\
$\left.\mathbf{W}_{\mathbf{1}}-\mathbf{W}_{\mathbf{2}}\right) /\left(\mathbf{W}_{\mathbf{2}}-\mathbf{W}_{\mathbf{0}}\right) \mathbf{1 0 0} \%$ & & $15.47 \%$ & \\
Average & & & \\
\hline
\end{tabular}

The overall enset fiber test and some its implication based on literature are shown in Table 4.

Table 4. Enset fiber test summary

\begin{tabular}{|c|c|c|}
\hline Fiber properties & Test result & Implication \\
\hline Cellulose (\%) & $62 \%$ & complex carbohydrate \\
\hline Hemicellulose (\%) & $19 \%$ & \\
\hline Moisture content (\%) & $15.47 \%$ & Absorbent \\
\hline Density $\left(\mathrm{Kg} / \mathrm{m}^{3}\right)$ & 690 & Light mater \\
\hline Lignin (\%) & $5 \%$ & $\begin{array}{l}\text { UV protective and } \\
\text { non-decomposable }\end{array}$ \\
\hline Single fiber Snap force (N) & 15.44 & Very strong material \\
\hline
\end{tabular}

\subsection{Strength Property of Fiber Reinforced Earthen Block}

a. Wet and dry mass of the specimen

For determination of fiber strength, block mass percent of fiber from $0-5 \%$ of enset vegetable fiber were added to earthen block and 44 blocks were casted These blocks of different masses were measured in wet condition and dry condition as described in Table 5 and Figure 6.

Table 5. Wet and Dry mass

\begin{tabular}{ccccc}
\hline $\begin{array}{c}\text { Name of } \\
\text { spacemen }\end{array}$ & $\begin{array}{c}\text { Fiber } \\
\text { \% }\end{array}$ & $\begin{array}{c}\text { Wet mass } \\
(\mathbf{K g})\end{array}$ & $\begin{array}{c}\text { Dry mass } \\
\mathbf{( K g )}\end{array}$ & $\begin{array}{c}\text { Change } \\
(\mathbf{K g})\end{array}$ \\
\hline NRB A0 & 0 & 5.314 & 3.168 & 2.146 \\
FRB A0.5 & 0.5 & 5.17 & 3.284 & 1.886 \\
FRB A1 & 1 & 5.15 & 3.255 & 1.895 \\
FRB A1.5 & 1.5 & 5.145 & 3.319 & 1.826 \\
FRB A2 & 2 & 5.09 & 3.481 & 1.609 \\
FRB A2.5 & 2.5 & 4.94 & 3.54 & 1.400 \\
FRB A3 & 3 & 4.92 & 3.575 & 1.345 \\
FRB A3.5 & 3.5 & 4.9 & 3.578 & 1.322 \\
FRB A4 & 4 & 4.891 & 3.518 & 1.374 \\
FRB A4.5 & 4.5 & 4.85 & 3.429 & 1.421 \\
FRB A5 & 5 & 4.82 & 3.233 & 1.587 \\
\hline
\end{tabular}




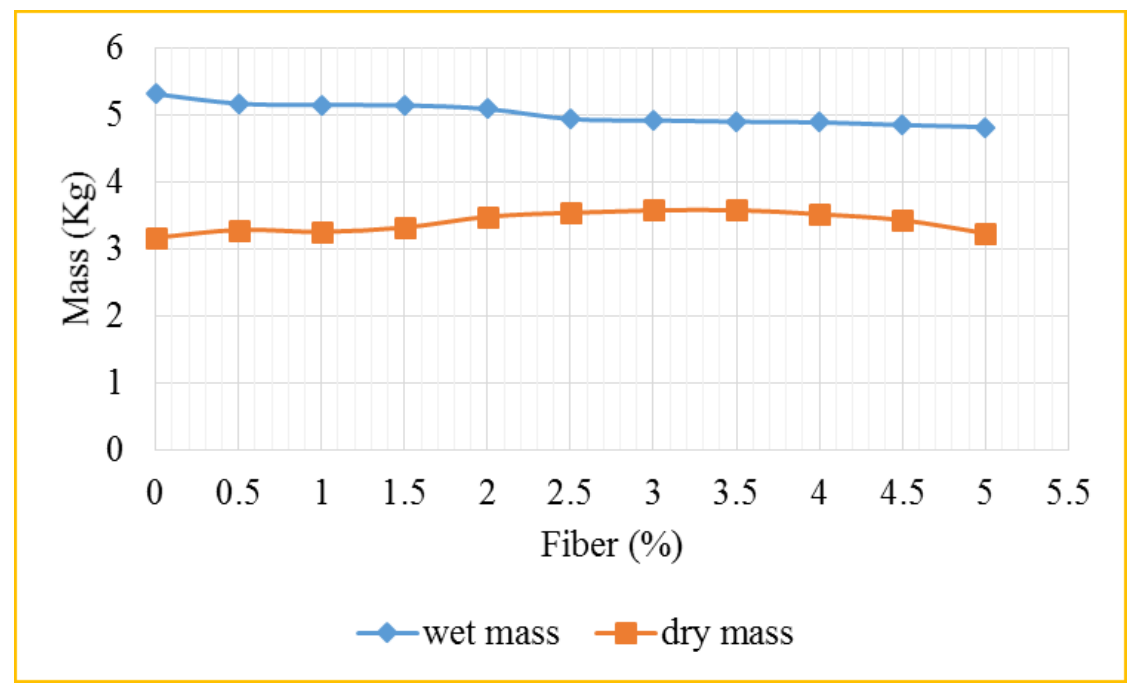

Figure 6. Wet and dry mass graph

From the table above, the mass of $0 \%$ fiber is $5.314 \mathrm{Kg}$ for wet mass highest from the total and the dry mass 3.5\% of fiber reinforced block mass is $3.578 \mathrm{Kg}$. This means increasing fiber amount more than $3.5 \%$ is decreasing the weight of the block. That is observed from this test increased fiber content the dry mass increased till 3.5\% of fiber then it was decreased.
Looking carefully in Figure 6 for increased fiber content from $0-5 \%$ the wet mass decreased and at the same time for increased fiber amount from $0-5 \%$ the dry mass increased up to $3.5 \%$ of fiber content and the graph bend to downward.

\section{b. Wet and dry volume of the specimen}

The volume of the block is different when it is in fresh state and dry state as seen in Table 6.

Table 6. Average wet and dry mass, volume and density

\begin{tabular}{|c|c|c|c|c|c|c|c|c|}
\hline $\begin{array}{l}\mathbf{N} \\
\mathbf{0}\end{array}$ & $\begin{array}{c}\text { Fiber } \\
(\%)\end{array}$ & $\begin{array}{c}\text { Specimen } \\
\text { Name }\end{array}$ & $\begin{array}{c}\text { Average wet mass } \\
(\mathrm{Kg})\end{array}$ & $\begin{array}{c}\text { Wet volume } \\
\text { m }^{3}\end{array}$ & $\begin{array}{c}\text { Wet density } \\
\mathrm{Kg} / \mathrm{m}^{3}\end{array}$ & $\begin{array}{c}\text { Dry mass average } \\
(\mathrm{Kg})\end{array}$ & $\begin{array}{c}\text { Dry volume } \\
\mathrm{m}^{3}\end{array}$ & $\begin{array}{c}\text { Dry density } \\
\mathrm{Kg} / \mathrm{m}^{3}\end{array}$ \\
\hline 1 & 0 & NRB A0 & 5.314 & 0.00324 & 1640.1 & 3.17 & 0.00105823 & 2993.7 \\
\hline 2 & 0.5 & FRB A0.5 & 5.17 & 0.00324 & 1595.7 & 3.28 & 0.00105838 & 3102.9 \\
\hline 3 & 1 & FRB A1 & 5.15 & 0.00324 & 1589.5 & 3.26 & 0.00186393 & 1746.3 \\
\hline 4 & 1.5 & FRB A1.5 & 5.145 & 0.00324 & 1588.0 & 3.32 & 0.00271839 & 1220.9 \\
\hline 5 & 2 & FRB A2 & 5.095 & 0.00324 & 1572.5 & 3.48 & 0.00275805 & 1262.1 \\
\hline 6 & 2.5 & FRB A2.5 & 4.94 & 0.00324 & 1524.7 & 3.54 & 0.00276747 & 1279.1 \\
\hline 7 & 3 & FRB A3 & 4.92 & 0.00324 & 1518.5 & 3.58 & 0.00277143 & 1289.9 \\
\hline 8 & 3.5 & FRB A3.5 & 4.9 & 0.00324 & 1512.3 & 3.58 & 0.00277182 & 1290.8 \\
\hline 9 & 4 & FRB A4 & 4.89 & 0.00324 & 1509.3 & 3.52 & 0.00277778 & 1266.5 \\
\hline 10 & 4.5 & FRB A4.5 & 4.85 & 0.00324 & 1496.9 & 3.43 & 0.00279955 & 1224.8 \\
\hline
\end{tabular}

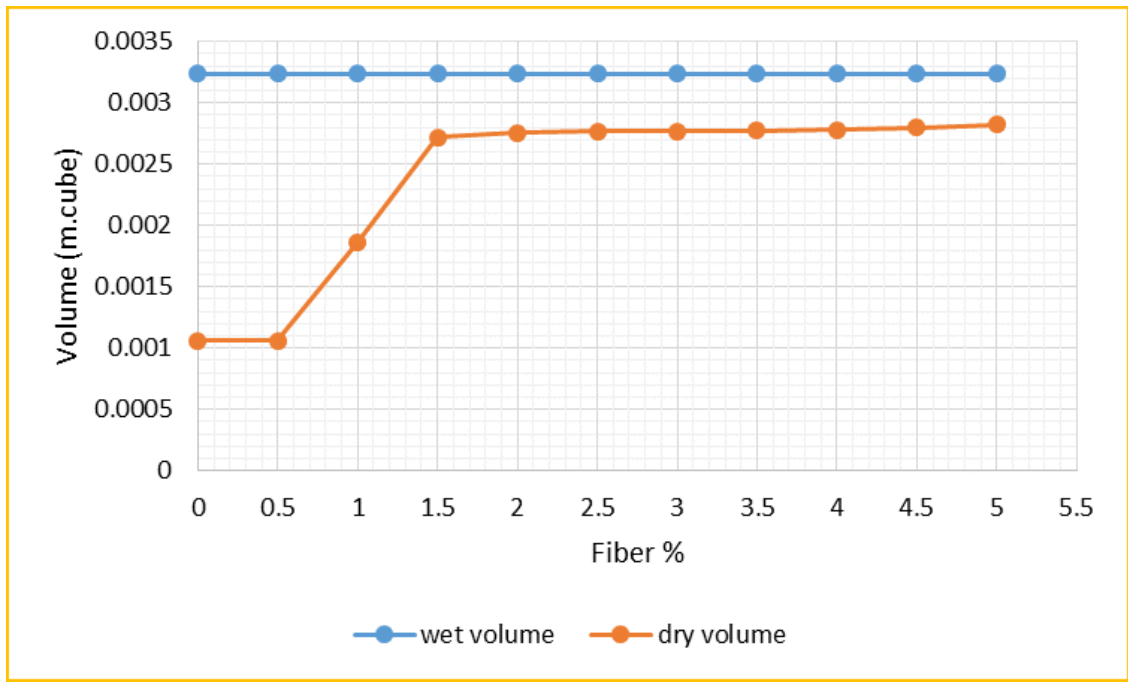

Figure 7. Wet and dry volume of the block 
From the literatures we can conclude that adding fiber to soil can decrease the shrinkage and this can also alters on volume of the block. Since the volume is the product of length, width and height; the lesser the shrinkage the higher the volume. We can see the wet and dry volume of fiber effect from Table 6 and also Figure 7 graph.

From Figure 7 we can see that wet volume of the block is constant $0.00324 \mathrm{~m}^{3}$ and the dray volume of the block varies from $0.001058 \mathrm{~m}^{3}-0.002821 \mathrm{~m}^{3}$. However, for increased fiber content $0.5-1.5 \%$ the volume increased linearly as seen in Figure 7 elliptical shape, which shows the attainable volume for fiber added block is up to $1.5 \%$, then the graph goes to $\mathrm{X}$-axis slightly increasing this also alter the density of the block.

\section{c. Wet and dry density of the specimen}

Density of the block is a good parameter for earthen block as construction material as discussed in this paper Soil density varies depending up on soil structure mentioned on descrption of earthen block, soil blocks; its density varies from 1700 to $2200 \mathrm{Kg} / \mathrm{m}^{3}$ as descussed.
According to the German Building Standards (2012), stated that earth, even with a high straw content, is 'not combustible' if the density is higher than $1700 \mathrm{~kg} / \mathrm{m}^{3}$. For light earth/fiber mixes fire resistance can be enhanced with the use of earth or lime renders and plasters. The present researchers both wet and dry density are illustrated in blow Figure 8. From the graph we observe that that wet volume of any block lies between $1400-1650 \mathrm{~kg} / \mathrm{m}^{3}$ [12], described freshly dug soil has a density of 1000 to 1500 $\mathrm{kg} / \mathrm{m} 3$. So that the fresh block has good density. However dry density of the earth block in Figure 8 shows that for non-reinforced block is high and decreased until fiber content of $0.5 \%-1.5 \%$ and then almost the same for fiber content $1.5-4 \%$ but after $4 \%$ it is decreasing and the graph is slightly moving down ward. For fiber content $1 \%$ the block density is $1746.3 \mathrm{Kg} / \mathrm{m}^{3}$; which is in standard density (1700 to $2200 \mathrm{Kg} / \mathrm{m}^{3}$ ). The density of stabilized or reinforced mud block is achieved by compaction [13]. That the present researcher result is under these standard limitation.

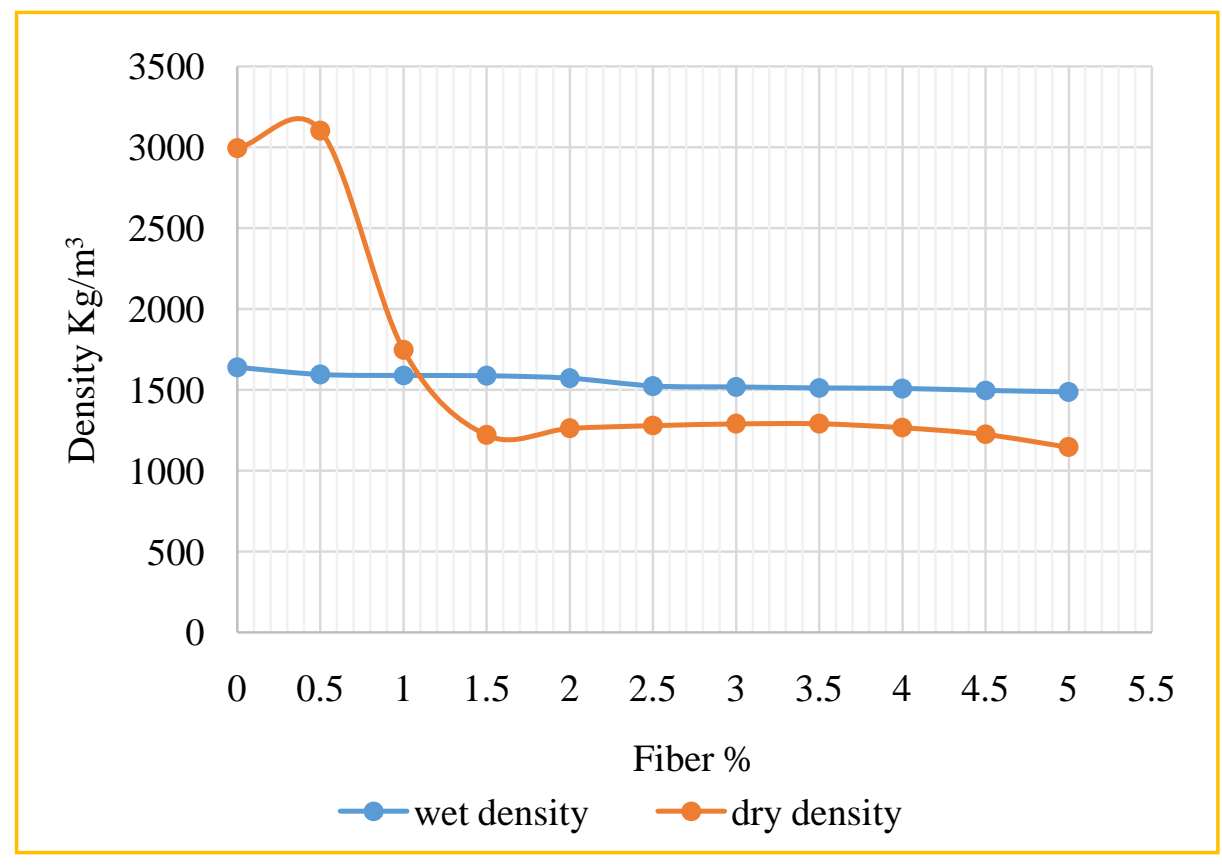

Figure 8. Dry and wet density relation

Table 1. Water absorption test

\begin{tabular}{|c|c|c|c|c|}
\hline Fiber \% & Specimen Name & $\begin{array}{l}\text { Weight before immersed } \\
\text { (W1) Kg }\end{array}$ & $\begin{array}{l}\text { Weight After immersed } \\
\text { (W2)Kg }\end{array}$ & Water absorption (\%) \\
\hline $\mathbf{0}$ & NRFB4 & 3.82 & fail & ND \\
\hline 0.5 & FRB4 & 3.71 & fail & ND \\
\hline 1 & FRB4 & 3.61 & fail & ND \\
\hline 1.5 & FRB2 & 3.56 & 4.08 & 14.61 \\
\hline 2 & FRB2 & 3.44 & 4.00 & 16.28 \\
\hline 2.5 & FRB2 & 3.43 & 4.04 & 17.78 \\
\hline 3 & FRB2 & 3.48 & 4.06 & 16.67 \\
\hline 3.5 & FRB2 & 3.31 & 3.87 & 16.92 \\
\hline 4 & FRB1 & 3.51 & 4.12 & 17.38 \\
\hline 4.5 & FRB2 & 3.41 & 4.05 & 18.77 \\
\hline 5 & FRB3 & 3.2 & 3.88 & 21.25 \\
\hline
\end{tabular}




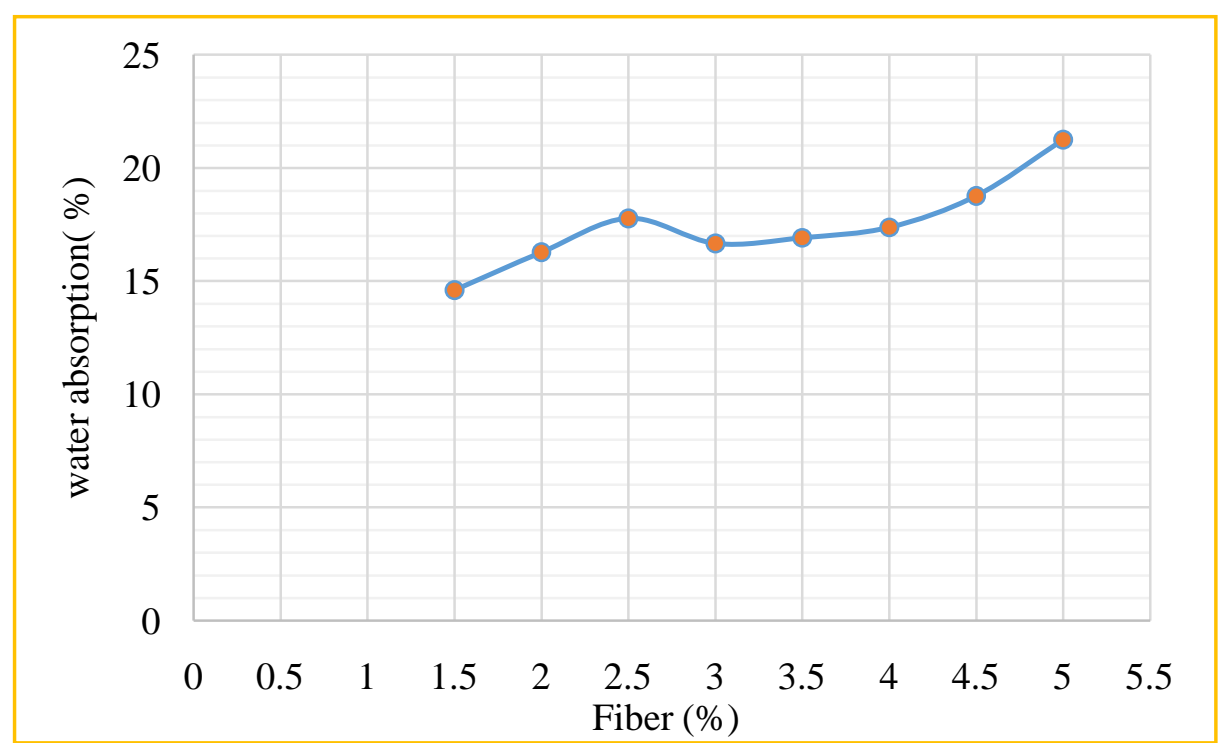

Figure 9. Water absorption test

\section{d. Water absorption test of the specimen}

The test result shown in Table 7 and Figure 9, for blocka $0 \%, 0.5 \%$ and $1 \%$, water absorption is unknown or the blocks are failed for the test. However for blocks 1.5\% of fiber content to $5 \%$ of fiber, the absorption increasing from $14.61 \%$ - 21.25\%. Different literatures suggest that the stength of earthen block is measured by its water absorvation as discussed in previous chapters.

According IS 1725: 1982, water absorption should not be more than $20 \%$ for class designation up to 12.5 and not more than $15 \%$ for class designation higher than this when immersed in cool water for 24 hours. According to UNBS (2011), the US 849 technical considerations for ISSBs, the maximum water absorption at max $15 \%$ of original mass.

\section{e. Compressive and flexural strength}

One of the specific objective of this study is to determine enset fiber reinforced earthen block compressive and flexural strength.

Comparsion that non-reinforced $(0 \%)$ and reinforeced $0.5 \%$ are broken accordingly to the block compressive strength standard 4.7 and 5.2 respectively the left blocks are stretching rather broken. It impossible to break in machine for 20-30 minutes and left for other tests. For that much amazing the fiber reinforced earthen block for fiber content $3 \%$ is dropped from the height of $7 \mathrm{~m}$ and did not break, dropping this block at the same height continuously it collapsed after $5^{\text {th }}$ drop from the height.

According to Banker-Hix (2014) fiber reinforced specimens failed in compressive test method, the addition of fibers prevented the CEB from separating in a brittle fashion. The same situation happened for present researcher exampler.

This shows how much strength the fiber reinforced block is and the application should be suggested for construction. Comparing its strength with fired clay brick and hollow concrete block (HCB); dropping them from $1-1.5 \mathrm{~m}$ height they will be crashed and this property is not seen in FREB. According to Mostafa \& Nasim (2016), Kerali (2001), Saul (2006) and (DIN 18 954) the minimum compressive strength of earthen block is $2 \mathrm{~N} / \mathrm{mm}^{2}$. So that the present researcher has got for nonreinforced and 0.5\% FREB block itself in the range which is greater than $2 \mathrm{~N} / \mathrm{mm}^{2}$ and the present researcher described the scope for rural settlement dwellers; that the building material can be used for low rise building.

The flexural strength of the FREB is tested and the result is shown on Figure 10. For the increased in fiber content from $1-3 \%$, the stress is increased from 1 to 2 and decreased from 2 to 3 . But for fiber content which is chopped in to size $1 \mathrm{~cm}$ to $1.5 \mathrm{~cm}$ of $2.5 \%$ fiber the stress is $1.557 \mathrm{MPa}$, which is for non-cut fiber stress between 1 and 2 percent.

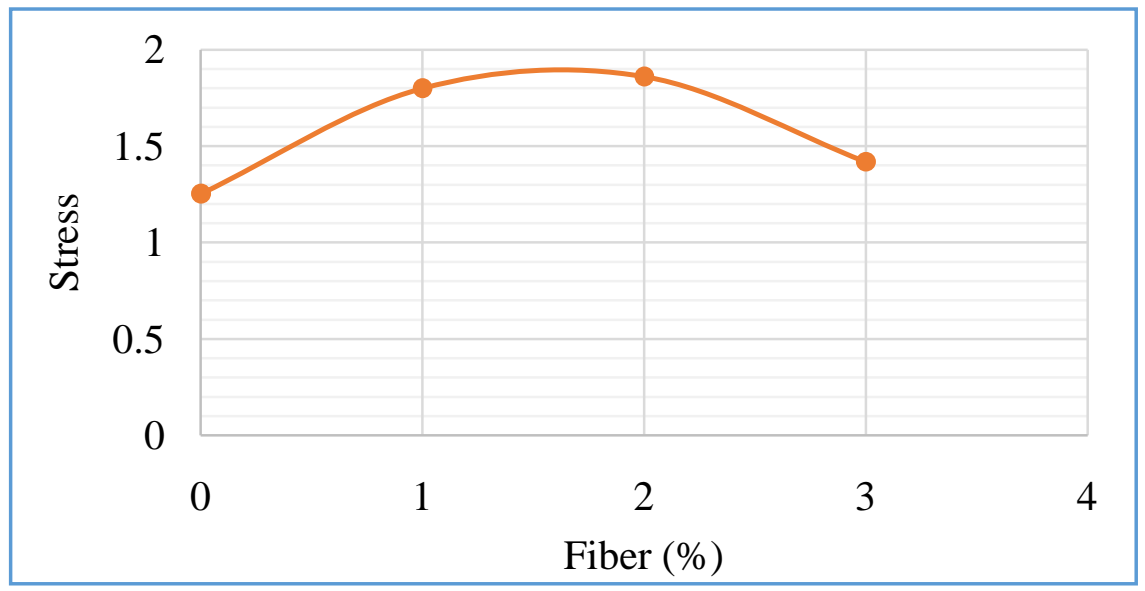

Figure 10. Flexural strength 


\section{Conclusions}

The principal objective of this research was to develop non-structural earthen wall construction material stabilized with enset vegetable fibers for rural dwelling units specifically SNNPR state Tarcha Town Sore neighborhoods. The research materials (enset vegetable fiber and clay soil) collected from the study area.

The clay soil collected from study area conceded out some basic properties of soil as construction material in laboratory like (grain size distribution, Atterbergs' limit and specific gravity) were suitable for earthen block production as per as stabilization with other substances like enset vegetable fiber for durability and other parameters.

The organic composition shows that $62 \%$ cellulose, hemicellulos 19\% and lignin 5\%. This composite material, is good construction material. Single fiber pull out test indicates that a very thin fiber diameter of $0.07 \mathrm{~mm}$ can resist the dead load of $10.39 \mathrm{~N}$ and $0.21 \mathrm{~mm}$ can resist dead load of $20 \mathrm{~N}$ and have average stress of $0.2341 \mathrm{~N} / \mathrm{mm}^{2}$.

The compressive and flexural strength of earthen block reinforced with enset vegetable fiber enabled different strength for increasing fiber amount from $0 \%-5 \%$. Whereas increased amount of fiber in the block decreased both wet and dry density of the block and adding excess amount of fiber to the block can opposite the standards; and lowering the connection of soils inside joints; that is adding $1.5 \%$ of fiber to mold is submitted as standard requirement for density achievement. On the other hand, testing its compressive strength accordance with ASTM C116-90 method is difficult because fiber has tensile behavior by nature and mixed with soil and dried in air, it had stretching performance is exemplary. Water absorption test of the block showed that, for blocks $0 \%$, $0.5 \%$ and $1 \%$ of fiber contents, the test failed, whereas for fiber content $1.5 \%-5 \%$, water absorption is increased and the standard suggestion of water absorption found at $1.5 \%$ of fiber added block is $<15 \%$ and which is recommended value as from the standard.

\section{Recommendations}

Earthen block reinforced with enset fiber is low cost because local available, simplest, easily shaped during casting, available where enset growing regions, low energy input, durable when casted properly and plastered well and environmental friendly.

The FREB technology has all of these properties mentioned on the above. Therefore, the researcher believe that this technology will add one advancement to the
Ethiopian society. As for the FREB technology to be accepted as the new construction method these viewpoints must be considered; sustainability, economy and attitudes.

Even though the researcher delimited its study area for rural settlement and non-structural wall construction material; the flexural strength indicates that this building material is working for urban low-rise building and also for structural purpose.

To enter in the market as entrepreneur manual pressing machine and fiber chopping instruments will be suggested for the owner and compaction will be achieved.

For more advanced use of enset vegetable fiber in construction industry it needs additional investigation and inventive research in the future

\section{References}

[1] D. Donath, "Experimental prototypes for emerging housing," Sustainable Futures: Architecture and Urbanism in the Global South, 2012.

[2] V. Yadav and T. M.K., "Study of Stablized soil bricks and Its compressive Strength," International Journal of Information Technology and Management, vol. 4, 2015.

[3] S. Brzev and B. Marcial , "Earthquake-Resistant Construction of Adobe," 2003.

[4] T. Asmamaw, "Study of Compressed Cement Stablize block as ana Alternative Wall Making Material," 2007.

[5] M. Habtemariam, "Study of Stablized Mud blocks as an Alternative Building Material and Development of models," 2012.

[6] A. Emma and W. Hanna, "Adobe-Technology of Everybody: Low Cost Housing in Ethiopia," Halmstad University, Halmstad, 2013.

[7] S. Ermiyas, "Design and Analysis of thick portion wall for building from local composite "enset fiber", 2011.

[8] M. Gonzalez, "Physical properties of unfired, extruded clays reinforced with low cost additives," University of Bath, 2012.

[9] F. D. Ching, Architecture;Form Space and Order, 3 ed., 2007.

[10] IS 3495, "Indian Standard methods of," 1992.

[11] M. Muller, V. piter and R. Alessandro, "Strength charactersitics of Untreated short-fiber composites from the plant Enset Ventricosum," Bioresources.com, vol. 1, no. 12, pp. 255-269, 2017.

[12] G. Minke, Building with Earth, Berlin, 2009.

[13] W. A. Banker-Hix, "The Effect of Clay, Cement and Fibers on the Strength and Durability of Compressed Earth Blocks," Master of Science in Civil and Environmental Engineering, 2014.

[14] National Research Council, "Lost Crops of Africa: Volume II: Vegetables," The national academies press, Washington DC, 1996.

[15] S. A. Brandt, S. Anita, H. Clifton, M. J. Terrence, T. Endale, D. Mulugeta, W.-M. Gizachew, Y. Gebre, S. Masayoshi and T. Shiferaw, "The tree against hunger: Enset-Based Agricultural Systems in Ethiopia," American Association for the Advancement of Science, Florida, 1997.

[16] ASTM D422-63, "Standard Test Method for Particle-Size Analysis of Soils," 1998.

[17] S. N. Saul, "Development of Cost-Effective Earthen Building Material for Housing Wall Construction," 2006. 